\title{
Electronic structure of polythieno[3,4-b]-thiophene-co- benzodithiophene (PTB7) derivatives for organic solar cell applications
}

\author{
Juan Carlos Roldao a, Eliezer Fernando Oliveira a , Francisco Carlos Lavarda a, b, * \\ ${ }^{a}$ UNESP - Univ Estadual Paulista, POSMAT - Programa de Pós-Graduação em Ciência e Tecnologia de Materiais, Bauru, SP, Brazil \\ ${ }^{\mathrm{b}}$ DF-FC, UNESP - Univ Estadual Paulista, Av. Eng. Luiz Edmundo Carrijo Coube 14-01, 17033-360 Bauru, SP, Brazil
}

\section{A R T I C L E I N F O}

\section{Article history:}

Received 17 February 2016

Received in revised form

22 March 2016

Accepted 22 March 2016

Available online 31 March 2016

\section{Keywords:}

Computational modeling

DFT

Chemical modifications

PTB7

Organic solar cells

\begin{abstract}
A B S T R A C T
Among the new materials currently employed as electron donor element in active layers of organic solar cells (OSCs), PTB7 holds the best results. It has been extensively studied and now there is a search for new derivatives to improve its properties. In this work, a set of 24 polymers derived from polythieno[3,4b]-thiophene-co-benzodithiophene (PTB7) was studied theoretically, using chemical modifications in the benzodithiophene (BDT) moiety of the PTB7 monomeric units. After evaluations of the electronic and optical properties, including the open circuit voltage and exciton dissociation and recombination conditions, the results indicate that employing chlorine as substituent yields the most promising material for application in active layers together with Phenyl- $C_{61}$-Butyric-Acid-Methyl-Ester (PCBM) as electron acceptor material.
\end{abstract}

(C) 2016 Elsevier B.V. All rights reserved.

\section{Introduction}

Since the 1980s, intense research has been focused on producing organic solar cells (OSC) more efficient than that conventional made of silicon [1]. Currently, the most efficient OSCs are those in which the active layer is produced by mixing conjugated electron donor polymers with molecules of Phenyl- $\mathrm{C}_{61}$-Butyric-AcidMethyl-Ester (PCBM) as electron acceptor [2,3]. This type of active layer is known as bulk heterojunction (BHJ) [3]. BHJ OSCs have reached an efficiency in converting solar into electrical energy of around $11 \%$ [4]. However, studies suggest that the maximum theoretical efficiency that can be achieved is $13 \%$, employing the conventional polymers already used in OSCs and through other improvements in $\mathrm{BHJ}$ processing [5].

In order to improve the efficiency of $\mathrm{BHJ}$ OSCs, and perhaps even exceed the theoretical limit of $13 \%$, it is necessary to find new polymeric materials that have improved intrinsic properties than those currently employed $[2,5,6]$. Several methods have been proposed in the literature with the aim of synthesizing new electron donor polymers, the most common being the synthesis of new copolymers [7-9] and the use of chemical substitutions in existing

\footnotetext{
* Corresponding author. DF-FC, UNESP - Univ Estadual Paulista, Av. Eng. Luiz Edmundo Carrijo Coube 14-01, 17033-360 Bauru, SP, Brazil.

E-mail address: lavarda@fc.unesp.br (F.C. Lavarda).
}

polymers $[2,10]$. We have shown in previous studies, in which chemical modifications were performed in the empty beta-position of poly(3-hexylthiophene) (P3HT) monomeric units, that it was possible to obtain new materials that exhibit improvements in bandgap, solubility or ionization potential [11,12], and when considering a combination of these with PCBM, it was possible to find new blends that could increase the efficiency of the OSC [12].

Polythieno [3,4-b]-thiophene-co-benzodithiophene (PTB7), as shown in Fig. 1, is a copolymer, recently proposed in the literature, that has shown very promising properties for application as electron donor material in active layers of OSC [13-17], making it a possible alternative to the widely employed P3HT [15]. Modifications made in PTB7 have been reported in the literature, mainly in the side chains and performed in the benzodithiophene (BDT) or the thienothiophene (TT) moieties that compose the monomeric units. This has led to new polymers with different properties that are sometimes more interesting than those of PTB7 [4,14,15].

In this work, we conducted a theoretical study on chemical modifications in the BDT moiety of the monomeric units of PTB7 in which we replace the hydrogen atoms of positions 1 and 2 , as depicted in Fig. 1, with small substituents with charge releasing or withdrawing properties. We have chosen to modify the main chain, since there have been few attempts to employ chemical substitutions in this part of the PTB7 monomer. The results yielded new materials with modified frontier orbital energies compared to 


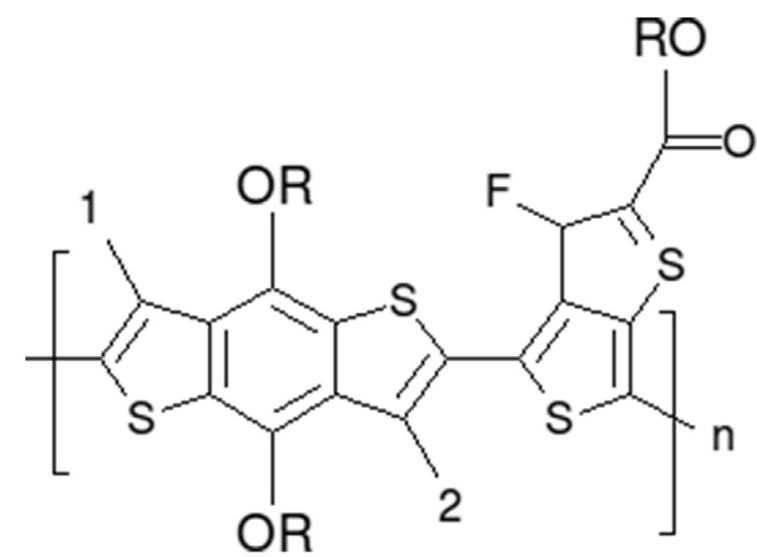

Fig. 1. Structure of the monomer of PTB7 and its derivatives $(R=2$-ethylhexyl).

PTB7, especially the derivative with chlorine, which showed electronic properties very close to those reported in the literature as the best in relation to PCBM as electron acceptor [7].

\section{Materials and methodology}

To build the PTB7 derivatives, the following substituents were selected: chlorine $(\mathrm{Cl})$, bromine $(\mathrm{Br})$, fluorine $(\mathrm{F})$, hydroxy $(\mathrm{OH})$, cyano $(\mathrm{CN})$, amino $\left(\mathrm{NH}_{2}\right)$, methyl $\left(\mathrm{CH}_{3}\right)$ and ethenyl $\left(\mathrm{CH}=\mathrm{CH}_{2}\right)$. For each substituent, the substitutions were performed at positions 1,2 and both in the PTB7 monomeric units (see Fig. 1), totaling 24 new PTB7 derivatives. Regarding the nomenclature adopted to refer to PTB7 derivatives, assuming a substituent X, we used PTB7-X-1 for substitution at position 1, PTB7-X-2 for substitution at position 2 and PTB7-X-12 for substitutions at both positions. Substituents with different charge releasing/withdrawing effects [18] were chosen in order to enhance the variations caused in the frontier electronic levels of the polymer when these substituents are inserted in the material. It should be noted that small substituents were chosen to fit between neighboring 2-ethylhexyl side chains.

To analyze the electronic properties of PTB7 and its derivatives, the oligomers approach was adopted $[19,20]$ in which the electronic and optical properties of the homopolymers and copolymers are estimated through an extrapolation method from the oligomers' results $[12,19,20]$. Due to the size of the monomeric unit of PTB7 and the derivatives, oligomers ranging from one to five monomeric units were used for each case analyzed.

Considering the size and quantity of the structures to be studied and the exclusive use of ab-initio methods that would result in a considerable computational cost, we optimized the geometric structures through the Hartree-Fock semi-empirical method PM6 [21], as implemented in the computational package MOPAC2012 [22]. We chose the PM6 because of its satisfactory performance reported in the literature in studies of conjugated polymers [20,23-27]. After the geometry optimization, data regarding the electronic structure of the studied structures was obtained through the Density Functional Theory (DFT), employing the hybrid functional B3LYP $[28,29]$ with the software GAUSSIAN09 [30] and the basis function set $6-31 \mathrm{G}(1 \mathrm{~d})$ [31]. This methodology has been applied in studies of conjugated polymers, proving suitable for obtaining good results $[24,32,33]$. Simulation of optical absorption spectra, i.e., the allowed vertical transition energies ( $E_{\text {vert }}$ ), were calculated using the Time Dependent Density Functional Theory (TD-DFT) [34] with the same functional, basis function set and software employed to obtain the electronic structure of the studied structures.
The literature reports some theoretical and experimental studies suggesting that the most probable conformation of the PTB7 main chain is fully coplanar, in accordance with the expected in the solid state $[14,35,36]$; however, as we will also study some PTB7 derivatives, we must analyze if the substituents are able to cause distortions in the main chain of the polymer, making it less planar. Thus, we conducted a preliminary study to evaluate the initial conformations of the geometric structures that would be adopted for this study. For this, we built a structure for PTB7 and each of its derivatives studied using three parallel oligomeric chains, which we referred to as a "sandwich". The central chain had two monomeric units, and the other two on the borders had four monomeric units; the oligomeric backbone and the side chains were predisposed initially coplanar with an interchain distance of approximately $4 \AA$, as observed for some polymers in the solid state $[35,37,38]$. Fig. 2 presents the initial conformation of the PTB7 sandwich before geometry optimization. The oligomeric chains on the borders have a larger number of monomeric units in an attempt to eliminate the border effects on the central chain. The optimization of all geometric parameters of the central oligomeric chain was allowed, however, for that of the borders we kept the backbone restricted to the plane, and the alkyl side chains were set free to optimize. The geometry optimization of the studied sandwiches were made using the PM6 method, with the addition of the Grimme approximation [39] in order to incorporate the Van der Waals interactions between the chains.

After completing geometry optimizations of the sandwiches discussed above, it was verified that the side chains tend to be coplanar to the plane of the oligomeric backbone. By analyzing the distortions that occur in the central oligomeric chain, dihedral angles of at most $7^{\circ}$ out of total planarity were noted. According to studies conducted by Zade and Bendikov [40], polymers in the solid state may have dihedral angles up to $36^{\circ}$ out of planarity, but up to $16^{\circ}$ no significant variations were observed in the energy of the lowest unoccupied and highest occupied molecular orbitals (LUMO and HOMO, respectively) or in the energy gap $\left(\Delta \mathrm{E}_{\mathrm{HL}}\right)$ between the energies of the LUMO ( $\left.\mathrm{E}_{\mathrm{LUMO}}\right)$ and the HOMO ( $\left.\mathrm{E}_{\mathrm{HOMO}}\right)$ [40]. As in this work we want study the energies of the frontier molecular orbitals, we decided to check whether the energies $\mathrm{E}_{\text {HOMO }}$ and $\mathrm{E}_{\mathrm{LUMO}}$ (and consequently $\Delta \mathrm{E}_{\mathrm{HL}}$ ) obtained for the central oligomers of the sandwiches were significantly different from those obtained for totally coplanar. As variations smaller than $0.1 \mathrm{eV}$ in energies $\mathrm{E}_{\mathrm{HOMO}}, \mathrm{E}_{\mathrm{LUMO}}$ and $\Delta \mathrm{E}_{\mathrm{HL}}$ were observed between the sandwiched oligomers and those totally planar, we decided to conduct our studies with fully planar oligomers.

After deciding to study planar oligomeric chains of PTB7 and its derivatives, we replaced the 2-ethylhexyl side chains with methyl groups, an approach that is proven to be feasible for planar structures, so that the electronic and optical properties remain practically unchanged $[23,41-43]$.

The optical and electronic properties of the polymers were estimated theoretically using the oligomers approach, in which extrapolation of the results obtained for the oligomers were made. The most common extrapolation methods are the Kuhn fit (Equation (1)) [44], the exponential mixed Kuhn fit (Equation (2)) [45,46], the Meier fit (Equation (3)) [47], the linear fit (Equation (4)) [26] and the 3rd degree polynomial fit (Equation (5)) [48]. In the equations below, $E$ is the orbital energy, $N$ is the number of double bonds in the main chain, $n$ is the number of monomer units and the remaining constants are adjustable parameters. However, it has been observed in studies with oligomers that there is no better method of fitting, some of which often have more consistent results for the energy of HOMO orbitals and others for LUMO orbitals. So, to choose the extrapolation method of optical and electronic properties that we would use throughout the study, we decided to make 

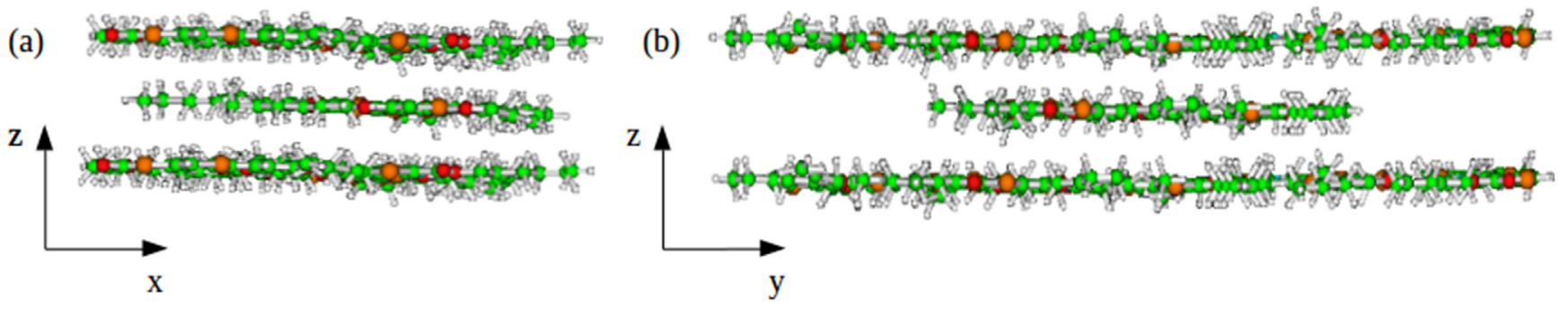

Fig. 2. Initial PTB7 3-chains structure submitted to geometry optimization with chain axis along y direction: (a) front view and (b) side view.

an initial analysis for PTB7, comparing our theoretical results with the published experimental data. Table S1 in the Supplementary Material presents the results obtained for the $\mathrm{E}_{\mathrm{HOMO}}, \mathrm{E}_{\mathrm{LUMO}}, \Delta \mathrm{E}_{\mathrm{HL}}$ and $E_{\text {vert }}$ extrapolations of PTB7. It is possible to conclude that extrapolations made with the Meier fit (Equation (3)) had the lowest overall deviation (around 6\%) compared to other methods. Thus, we decided to use the Meier fit to obtain all extrapolated properties for PTB7 and its derivatives.

$$
\begin{aligned}
& E(N)=E_{0} \sqrt{1-A \cos \left(\frac{\pi}{N+1}\right)} \\
& E(N)=E_{0} \sqrt{1-A \cos \left(\frac{\pi}{N+1}\right)}-B e^{-C N} \\
& E(n)=E_{\infty}+\Delta E e^{-1(n-1)} \\
& E(x)=a x+b, \text { where } x=\frac{1}{n}
\end{aligned}
$$

$E(x)=a x^{3}+b x^{2}+c x+d$, where $x=\frac{1}{n}$

\section{Results and discussion}

\subsection{Optical and electronic properties of PTB7 derivatives}

The experimental values for $\mathrm{E}_{\mathrm{HOMO}}, \mathrm{E}_{\mathrm{LUMO}}, \Delta \mathrm{E}_{\mathrm{HL}}$ and $\mathrm{E}_{\mathrm{vert}}$ of PTB7 are, respectively, $-5.15,-3.31,1.84$ and $1.68 \mathrm{eV}$ [14]; regarding our results, we find deviations of 5.6, 10.4, 3.2 and 5.5\% for $\mathrm{E}_{\mathrm{HOMO}}$, $\mathrm{E}_{\mathrm{LUMO}}, \Delta \mathrm{E}_{\mathrm{HL}}$ and $\mathrm{E}_{\mathrm{vert}}$, respectively. In the literature, theoretical studies with polymers employing DFT/B3LYP have shown deviations up to $10 \%$ for the electronic properties in relation to the experimental data can be found [32]; thus, the deviations found for the electronic properties of PTB7 in this study are in accordance with the adopted methodology. Regarding the electronic properties of the 24 PTB7 derivatives, the results obtained for $\mathrm{E}_{\mathrm{HOMO}}, \mathrm{E}_{\mathrm{LUMO}}$, $\Delta \mathrm{E}_{\mathrm{HL}}$ and $\mathrm{E}_{\mathrm{vert}}$ can be seen in Table S2 of the Supplementary Material, together with the percentage variations in relation to PTB7 properties. As we know, there is already a percentage deviation in the theoretical data obtained for PTB7. For the derivatives, there should be a double deviation, i.e., a percentage variation compared to the theoretical PTB7 data, which already has a percentage variation over the experimental data. To improve the reliability of our study, we employ scale factors (SF) on the theoretical data of PTB7 derivatives. Thus, using the theoretical and experimental data for PTB7, the theoretical values for $\mathrm{E}_{\mathrm{HOMO}}, \mathrm{E}_{\mathrm{LUMO}}, \Delta \mathrm{E}_{\mathrm{HL}}$ and $\mathrm{E}_{\mathrm{vert}}$ of PTB7 and its derivatives were multiplied by the following SFs: $\mathrm{SF}_{\mathrm{HOMO}}=(5.15 / 4.86), \mathrm{SF}_{\mathrm{LUMO}}=(3.31 / 2.96), \mathrm{SF}_{\Delta \mathrm{EHL}}=(1.84 / 1.89)$ and
$\mathrm{SF}_{\text {Evert }}=(1.68 / 1.69)$. The new scaled data of the electronic structure of PTB7 and its derivatives are shown in Fig. 3 (these data are reproduced in Table S3 in the Supplementary Material). As can be seen in Fig. 3, the use of chemical substitutions in PTB7 resulted in various new materials with modified optical and electronic properties.

Regarding the values obtained for $\mathrm{E}_{\mathrm{HOMO}}$, we noted that half of the derivatives showed lower values than the PTB7; the lowest value was for the PTB7-CN-12 derivative, with a $\mathrm{E}_{\mathrm{HOMO}}$ of approximately $-6.0 \mathrm{eV}$. The PTB7-OH-1 derivative had the highest $\mathrm{E}_{\mathrm{HOMO}}$, approximately $-4.3 \mathrm{eV}$. Interestingly, all derivatives that had a lower $\mathrm{E}_{\text {HOMO }}$ were those in which we employed electron withdrawing substituents [12]; it is known from the literature that electron withdrawing groups are able to stabilize the $\mathrm{E}_{\mathrm{HOMO}}$ energy of the material $[2,6]$, therefore, our results were consistent with the expected effect. The opposite occurs for the case in which we used electron releasing substituents, which promote destabilization in $\mathrm{E}_{\mathrm{HOMO}}$ [12]. In BHJ OSCs that employ PCBM as an electron acceptor, it is estimated that the ideal electron donor material possesses a value for $\mathrm{E}_{\mathrm{HOMO}}$ of approximately $-5.4 \mathrm{eV}$ [7]; compared to our results for PTB7 derivatives, the PTB7-CN-1, PTB7-CN-2, PTB7-Br-1, PTB7-Br-12, PTB7-Cl-1 and PTB7-Cl-12 were the cases in which the $\mathrm{E}_{\mathrm{Homo}}$ was closest to the ideal, so that these new materials appear promising for use in OSCs.

It is interesting that the materials used in the active layers of OSCs have a good stability to oxidation when exposed to the environment, which directly influences the device's lifetime. The oxidation stability of a material is proportional to its ionization potential (IP) [6,7]. With the results obtained for the $\mathrm{E}_{\mathrm{HOMO}}$, and using Koopmans Theorem [49], IP can be estimated as equal to the negative of $\mathrm{E}_{\text {номо }}$. According to Takimiya et al. [50], in order to have good oxidation stability, it is important that the material has an IP higher than $5.0 \mathrm{eV}$. In our results, we noted that, in addition to the PTB7, 15 derivatives met the condition of IP $>5.0 \mathrm{eV}$. It should be noted that the cases that presented an $\mathrm{E}_{\mathrm{HOMO}}$ close to the ideal for combination with PCBM also showed stability against oxidation.

Seven PTB7 derivatives had values of ELUMO smaller than that of PTB7, and the smallest was obtained for the PTB7-CN-12 derivative (approximately 26\% lower than PTB7); $\mathrm{PTB} 7-\mathrm{NH}_{2}-12$ presented the highest value for $\mathrm{E}_{\mathrm{LUMO}}, 15 \%$ higher than that of PTB7. The ideal value of $\mathrm{E}_{\mathrm{LUMO}}$ for the electron donor material to be used in combination with PCBM in BHJ OSCs is $-3.9 \mathrm{eV}$ [7]; PTB7-CN-1 and PTB7-Cl-12 presented an $\mathrm{E}_{\mathrm{LUMO}}$ of approximately $-3.7 \mathrm{eV}$, and they were the closest to the ideal. In combination with the analysis carried out previously for $\mathrm{E}_{\mathrm{HOMO}}$, we can see that the PTB7-CN-1 and PTB7-Cl-12 derivatives may be promising materials for use in active layers of BHJ OSCs with PCBM, once $\mathrm{E}_{\mathrm{HOMO}}$ and $\mathrm{E}_{\mathrm{LUMO}}$ are close to that which is considered as ideal.

Regarding $\Delta \mathrm{E}_{\mathrm{HL}}$ and $\mathrm{E}_{\mathrm{ver}}$, which are related to the absorption band of the solar spectrum that in turn has a direct impact on the electric current generated in OSCs, by decreasing $\Delta \mathrm{E}_{\mathrm{HL}}$ and $\mathrm{E}_{\mathrm{vert}}$ more photons can be collected by the material $[2,51]$. We noted that 


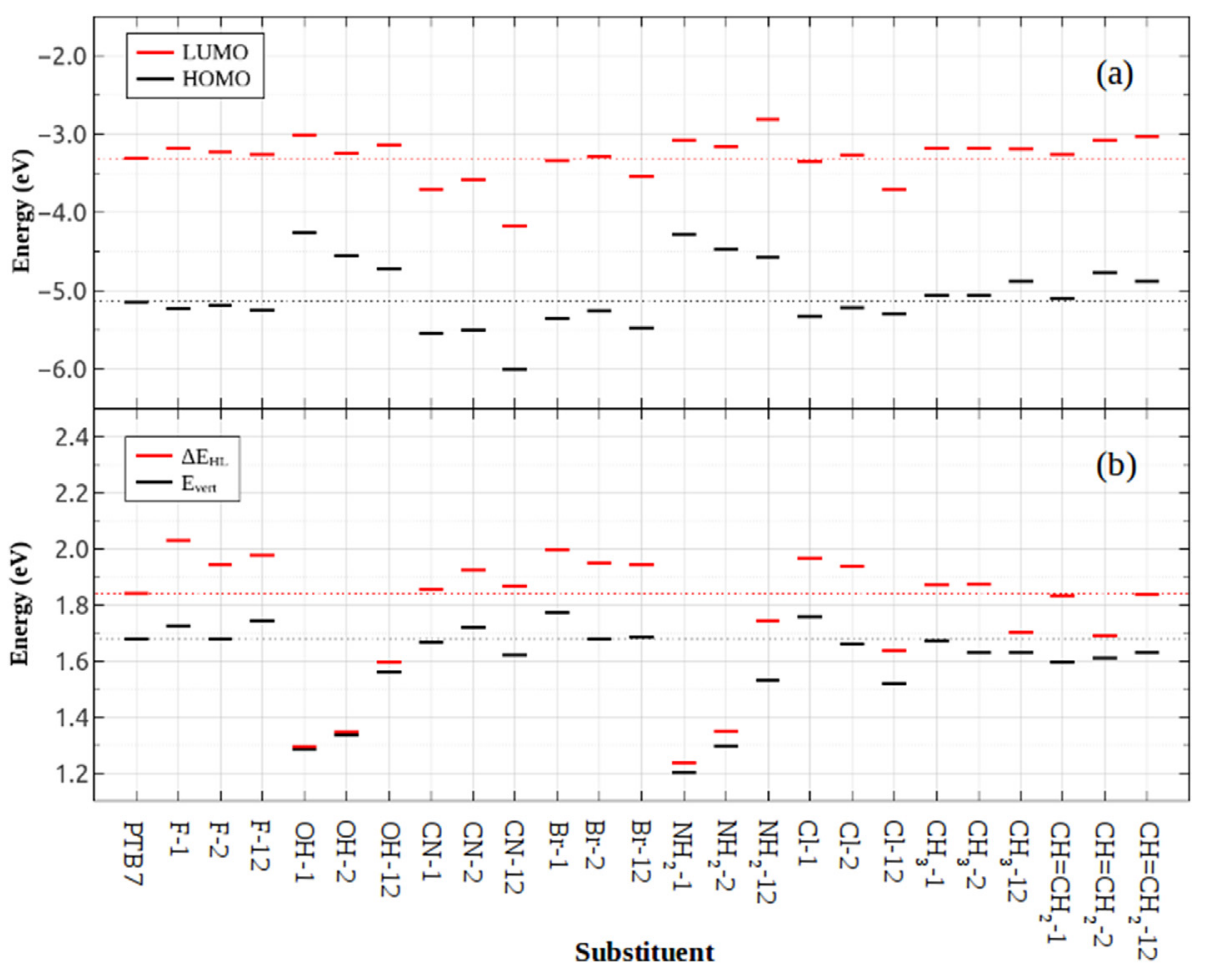

Fig. 3. Results obtained for (a) $\mathrm{E}_{\mathrm{HOMO}}$ and $\mathrm{E}_{\mathrm{LUMO}}$, and (b) $\Delta \mathrm{E}_{\mathrm{HL}}$ and $\mathrm{E}_{\mathrm{vert}}$ of PTB7 and derivatives; the dashed lines indicate the PTB7 values.

the derivatives substituted with the hydroxyl $(\mathrm{OH})$ and amine $\left(\mathrm{NH}_{2}\right)$ groups were those with the lowest $\Delta \mathrm{E}_{\mathrm{HL}}$ and $\mathrm{E}_{\mathrm{vert}}$, around $1.2-1.3 \mathrm{eV}$. It is known that using groups with strong electron releasing characteristics usually results in materials with low $\Delta \mathrm{E}_{\mathrm{HL}}$, but with a disadvantage in relation to the energy of the frontier electronic levels, which increase significantly, resulting in less stable materials $[11,12]$. The lowest results for $\Delta \mathrm{E}_{\mathrm{HL}}$ and $\mathrm{E}_{\mathrm{vert}}$ without loss of stability was achieved by the PTB7-Cl-12 derivative. As for the ideal $\Delta \mathrm{E}_{\mathrm{HL}}$ for use in OSCs, the literature points to a value of around $1.5 \mathrm{eV}$ [7]. We realize that PTB7 is a little above this value, however, the PTB7-Cl-12 derivative presented a result of $\sim 1.6 \mathrm{eV}$, which is closer to the ideal.

The PTB7-F-12 derivative has previously been synthesized and characterized experimentally [14]. According to the experimental data, when inserting fluorine atoms at both positions 1 and 2 in the BDT of PTB7 monomeric units, it was noted that a blueshift occurs in optical absorption, there is a slight lowering of $\mathrm{E}_{\mathrm{HOMO}}$ and a bandgap increase. The same was observed in our theoretical data for PTB7-F-12 in relation to PTB7 (see Fig. 3). This shows that the theoretical methodology used to study PTB7 and its derivatives corresponds to the trends. Therefore, if the predictions made for PTB7-F-12 are consistent with what is observed experimentally, it is possible that the estimates for other derivatives will be also.

It is interesting to note that the values of $\mathrm{E}_{\mathrm{HOMO}}$ and $\mathrm{E}_{\mathrm{LUMO}}$ of PTB7-Cl-12 are lower than those of the PTB7-F-12. This is counterintuitive, since it is known that fluorine has a higher tendency to withdraw electrons than the chlorine, which should make the energy of the orbitals most stable, with lower energy [6,7,52-55]. On the other hand, we know that $\mathrm{E}_{\mathrm{HOMO}}$ and $\mathrm{E}_{\mathrm{LUMO}}$ are much more sensitive to the effects of charge exchange via $\pi$ than $\sigma$ bonds, occurred between the polymer backbone and the substituent [12]. As fluorine have an electron donation through the $\pi$ system stronger than chorine [56], the frontier electronic orbitals are less stable for fluorine than chlorine substitution.

Overall, if we were to make a previous selection of a new electron donor material derived from PTB7 for BHJ OSCs with PCBM, taking into account only the optimum position for the frontier electronic levels and $\Delta \mathrm{E}_{\mathrm{HL}}$, we could choose the PTB7-Cl-12 derivative as the most promising. However, if we take into account other properties related to the operation of the OSC, perhaps other PTB7 derivatives may also be feasible for use; the next section will carry out such analyses.

\subsection{Prospects of the solar cell performance employing PTB7 derivatives and $P C B M$}

Several intrinsic properties of conjugated polymers have a direct influence on the efficiency of OSCs [2,6], and therefore, choosing a material for use in the active layer is indeed an important step [2]. A starting point for the selection of a particular material is to analyze the combination of the energies of the frontier electronic levels of the acceptor (A) and donor (D) materials [6]; through these, direct correlations with some of the properties of the device can be performed. Fig. 4 presents a sketch of the frontier electronic levels of donor and acceptor materials in the BHJ active layer of the OSC. Photons absorbed by the donor materials produce electron-hole pairs (excitons), which must be dissociated to generate free charge carriers $[2,57]$. The exciton dissociation will only occur if the difference, $\Delta E_{1}$, between the $L_{U M O}$ energy of the donor $\left(E_{L U M O, D}\right)$ and the energy of the $\mathrm{LUMO}_{\mathrm{A}}$ of the acceptor $\left(\mathrm{E}_{\mathrm{LUMO}, \mathrm{A}}\right)$ is at least equal to the exciton binding energy $\left(E_{b}\right)$ of the electron donor material [6,7]. When the exciton is dissociated, the hole remains in the donor material and the electron goes to the acceptor material; to prevent that the hole that remains in the donor material recombines with an electron of the acceptor material, we need to ensure that the difference, $\Delta \mathrm{E}_{3}$, between the energy $\mathrm{E}_{\mathrm{HOMO}, \mathrm{D}}$ of the donor and the energy $E_{\text {Номо }}$ of the acceptor is at least equal to $E_{b}$ $[6,51]$. The open circuit voltage $\left(\mathrm{V}_{\mathrm{oc}}\right)$ of the device is proportional to the energy difference, $\Delta E_{2}$, between the energies $E_{H O M O, D}$ and $E_{\mathrm{LU}}$ Mo,A [6]. The $\mathrm{V}_{\text {oc }}$ in the device also depends on other factors related 


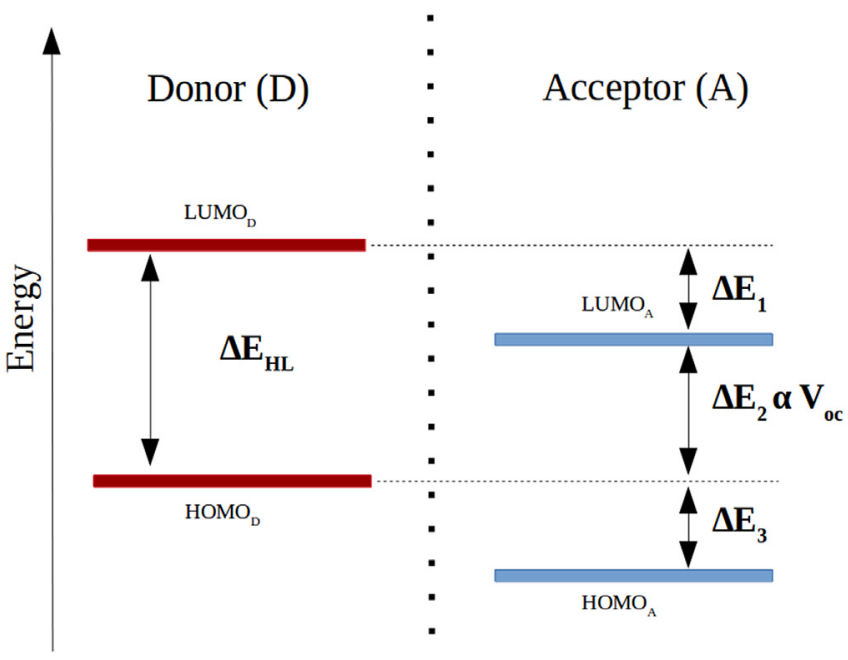

Interface D-A

Fig. 4. Energy levels sketch for acceptor and donor materials and the parameters that influence in the efficiency of the device.

to the morphology of the active layer $[2,6,7,51]$, however, experimental findings reinforce that if $\Delta \mathrm{E}_{2}$ is higher, an increased $\mathrm{V}_{\text {oc }}$ may be achieved $[2,6,7]$. Thus, we noted that the adjustment of the frontier electronic levels concurrently with the parameters $\Delta \mathrm{E}_{1}, \Delta \mathrm{E}_{2}$ and $\Delta E_{3}$ is extremely important to achieve a more efficient OSC.

Fig. 5 shows the results for $\Delta \mathrm{E}_{1}, \Delta \mathrm{E}_{2}$ and $\Delta \mathrm{E}_{3}$ with combinations made between PTB7 derivatives as electron donor materials and PCBM as electron acceptor. We also present the $E_{b}$ results that will be used to make comparisons with the parameters $\Delta \mathrm{E}_{1}$ and $\Delta \mathrm{E}_{3} ; \mathrm{E}_{\mathrm{b}}$ is estimated by subtracting $\Delta \mathrm{E}_{\mathrm{HL}}$ and $\mathrm{E}_{\mathrm{vert}}\left(\mathrm{E}_{\mathrm{b}}=\Delta \mathrm{E}_{\mathrm{HL}}-\mathrm{E}_{\mathrm{vert}}\right)$ [51]. The experimental data of the electronic structure of PCBM are $\mathrm{E}_{\mathrm{HOMO}}=-6.0 \mathrm{eV}$ and $\mathrm{E}_{\mathrm{LUMO}}=-4.2 \mathrm{eV}$ [7]. Table S4 in the Supplementary Material presents the data of Fig. 5.

As can be seen in Fig. 5(a) and (c), excepting PTB7-CN-12, the parameters $\Delta \mathrm{E}_{1}$ and $\Delta \mathrm{E}_{3}$ are larger than the $\mathrm{E}_{\mathrm{b}}$; this indicates that the use of chemical substitutions in PTB7 in general does not bring problems related to exciton dissociation and no recombination in the active layer in which the electron acceptor material is PCBM. Regarding the $\mathrm{E}_{\mathrm{b}}$, we obtained a value of $0.16 \mathrm{eV}$ for PTB7, which is in agreement with values observed in the literature [14,36]; seven derivatives have an $\mathrm{E}_{\mathrm{b}}$ smaller than that for PTB7, indicating that the exciton will be more easily dissociated. However, many of the derivatives that have an $\mathrm{E}_{\mathrm{b}}$ smaller than PTB7 also have an IP below the limit at which the material can be considered stable to oxidation.

In Fig. 5(b) the values for $\Delta \mathrm{E}_{2}$ are shown, which is proportional to the $\mathrm{V}_{\mathrm{oc}}$ reached in OSCs; the greater $\Delta \mathrm{E}_{2}$, the greater will be the $\mathrm{V}_{\text {oc. }}$. We observed that 12 PTB7 derivatives had a $\Delta \mathrm{E}_{2}$ larger than that for the combination PTB7/PCBM. It is known from the literature that achieving a $\mathrm{V}_{\mathrm{oc}}$ greater than $1 \mathrm{~V}$ is still a challenge [2]; experimentally, the combination PTB7/PCBM presents a $\mathrm{V}_{\mathrm{oc}}$ of around $0.74 \mathrm{~V}[14]$. Thus, the derivatives that yielded a $\Delta \mathrm{E}_{2}$ greater than that for PTB7/PCBM have the potential to optimize the $\mathrm{V}_{\mathrm{oc}}$ of the OSC, if employed in active layers together with PCBM.

Taking into account all the obtained results, we concluded that the PTB7-Cl-12 derivative is indeed a promising material, once it

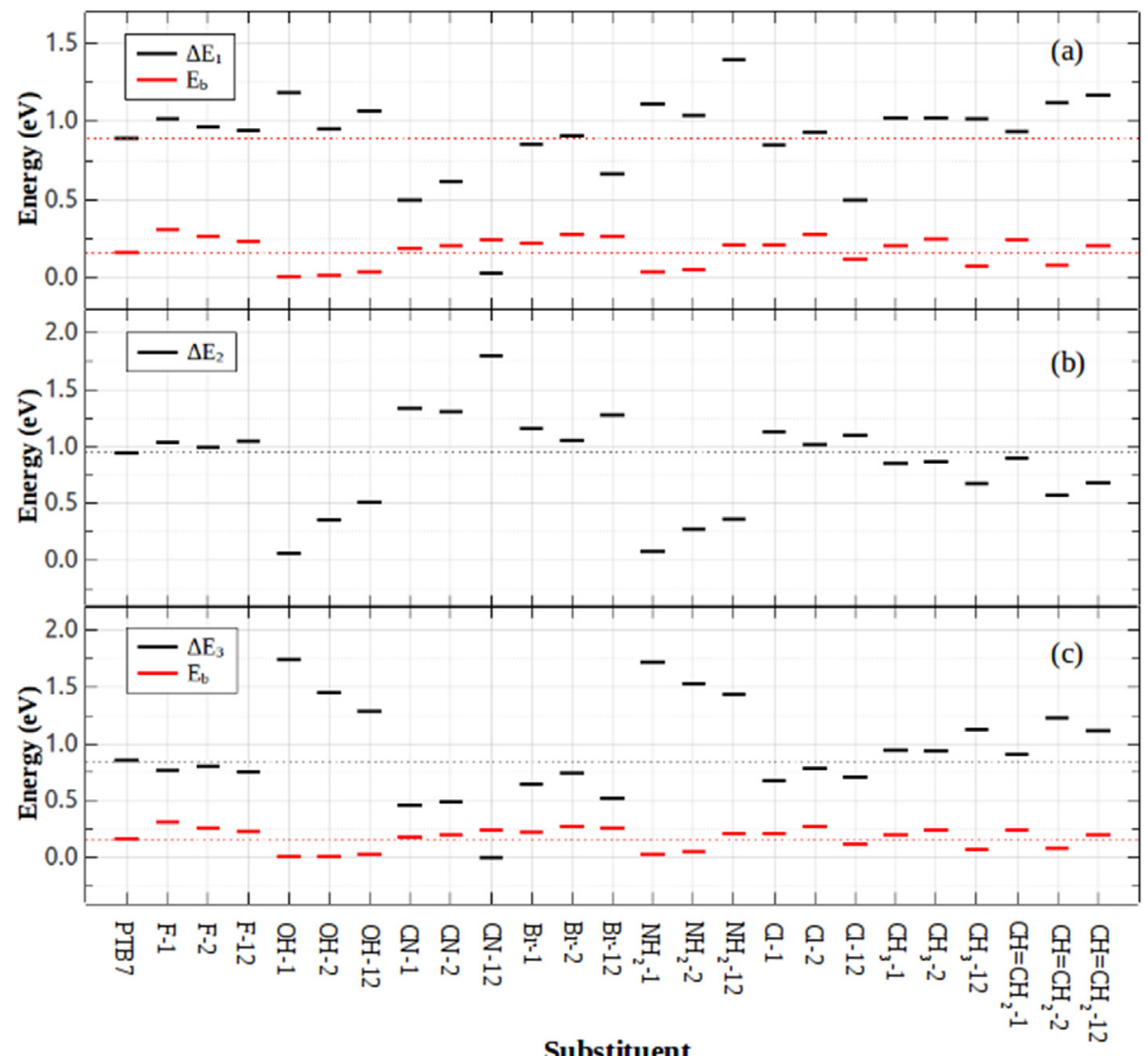

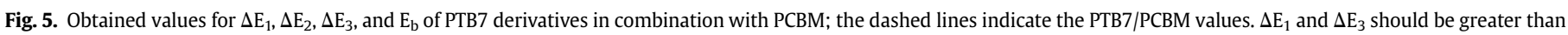
$\mathrm{E}_{\mathrm{b}}$. 
meets all the requirements for its use in active layers of $\mathrm{BHJ}$ OSCs that use PCBM as electron acceptor element. However, according to the results obtained for $\Delta \mathrm{E}_{1}, \Delta \mathrm{E}_{2}, \Delta \mathrm{E}_{3}$ and $\mathrm{E}_{\mathrm{b}}$, we noted that there are also other derivatives that may be taken into account, even if the position of the frontier electronic levels or $\Delta \mathrm{E}_{\mathrm{HL}}$ are not close to those considered ideal; this was the case for the derivatives PTB7-F1, PTB7-F-2, PTB7-F-12, PTB7-CN-1, PTB7-CN-2, PTB7-Br-1, PTB7$\mathrm{Br}-2$, PTB7-Br-12, PTB7-Cl-1 and PTB7-Cl-2. It is worth remembering that in this study the feasibility of employing PTB7 derivatives in $\mathrm{BHJ}$ OSCs that make use of PCBM as an electron acceptor was analyzed. Perhaps if we perform the same analysis, but with other electron acceptors, other PTB7 derivatives proposed by us might be the best options.

\section{Conclusions}

We studied the electronic and optical properties of 24 PTB7 derivatives in order to verify if any could present potential for application in BHJ OSCs. Chemical substitutions were made in the BDT moiety of the PTB7 monomeric units, and similar to other studies [11,12], it was observed that the use of chemical substitutions was able to provide new polymers derived from PTB7 with variation in the energies of the frontier electronic levels, ionization potential and bandgaps.

In BHJ OSCs that use PCBM as electron acceptor material, it is interesting that the electron donor material has $\mathrm{E}_{\mathrm{HOMO}}$ and $\mathrm{E}_{\mathrm{LUMO}}$ of approximately -5.4 and $-3.9 \mathrm{eV}$, respectively [7]. According to our results, $\mathrm{PTB} 7-\mathrm{CN}-1$ and $\mathrm{PTB} 7-\mathrm{Cl}-12$ presented the values for $\mathrm{E}_{\mathrm{HOMO}}$ and $E_{\mathrm{LUMO}}$ close to the value that is suggested as ideal, which make them good candidates for application in OSC. Regarding $\Delta \mathrm{E}_{\mathrm{HL}}$, it is estimated that a value around $1.5 \mathrm{eV}$ would be ideal [7]. We noted that the derivatives PTB7-OH-12 and PTB7-Cl-12 come close, with a $\Delta \mathrm{E}_{\mathrm{HL}}$ of approximately $1.6 \mathrm{eV}$; however, the electronic levels of the PTB7-OH-12 derivative are higher than would be ideal, destabilizing the material and making it unfeasible for employment in $\mathrm{BHJ}$ OSCs with PCBM.

The analysis of the parameters $\Delta \mathrm{E}_{1}, \Delta \mathrm{E}_{2}$ and $\Delta \mathrm{E}_{3}$, together with $E_{b}$, allowed us to verify that the use of chemical substitutions in PTB7 does not seem to cause problems for dissociation and no recombination of excitons. The only case in which a good compromise between the parameters $\Delta \mathrm{E}_{1}$ and $\Delta \mathrm{E}_{3}$, and $\mathrm{E}_{\mathrm{b}}$, was not found was for the PTB7-CN-12 derivative. In blends with PCBM, half of the derivatives studied could exhibit a $\mathrm{V}_{\text {oc }}$ greater than that observed for the combination PTB7/PCBM.

In fact, we found several interesting results in this study, but the most promising derivative to employ in the active layer of $\mathrm{BHJ}$ OSCs with PCBM was PTB7-Cl-12; this derivative had results close to the ideal for $\mathrm{E}_{\mathrm{HOMO}}, \mathrm{E}_{\mathrm{LUMO}}$ and $\Delta \mathrm{E}_{\mathrm{HL}}$, a good compromise between the parameters $\Delta \mathrm{E}_{1}$ and $\Delta \mathrm{E}_{2}$, and $\mathrm{E}_{\mathrm{b}}$, and suggests that it has a $\mathrm{V}_{\mathrm{oc}}$ greater than PTB7. We can not rule out the other PTB7 derivatives studied, since some cases also exhibit interesting electronic properties. Certainly, if additional analyses were conducted in this study, using another electron acceptor material, it is likely that other promising PTB7 derivatives for use in OSC would be found.

\section{Acknowledgments}

We would like to thank the Brazilian agencies CAPES and FAPESP (proc. 2012/21983-0 and 2014/20410-1) for financial support. This research was also supported by resources supplied by the Center for Scientific Computing (NCC/GridUNESP) of the São Paulo State University (UNESP).

\section{Appendix A. Supplementary data}

Supplementary data related to this article can be found at http:// dx.doi.org/10.1016/j.orgel.2016.03.029.

\section{References}

[1] M.C. Scharber, N.S. Sariciftci, Prog. Polym. Sci. 38 (2013) 1929, http:// dx.doi.org/10.1016/j.progpolymsci.2013.05.001.

[2] G. Li, R. Zhu, Y. Yang, Nat. Phot 6 (2012) 153, http://dx.doi.org/10.1038/ nphoton.2012.11.

[3] Y. Huang, E.J. Kramer, A.J. Heeger, G.C. Bazan, Chem. Rev. 114 (2014) 7006, http://dx.doi.org/10.1021/cr400353v.

[4] Z. He, B. Xiao, F. Liu, H. Wu, Y. Yang, S. Xiao, C. Wang, T.P. Russell, Y. Cao, Nat Phot 9 (2015) 174, http://dx.doi.org/10.1038/nphoton.2015.6.

[5] M.C. Scharber, Adv. Mater. 28 (2016) 1994, http://dx.doi.org/10.1002/adma. 201504914.

[6] Y. Li, Acc. Chem. Res. 45 (2012) 723, http://dx.doi.org/10.1021/ar2002446.

[7] H. Zhou, L. Yang, W. You, Macromolecules 45 (2012) 607, http://dx.doi.org/ 10.1021/ma201648t.

[8] H. Ahn, J.S. Moon, W.G. Kim, M.A. Uddin, J. Choi, C. Kim, H.Y. Woo, N. Kim, J.W. Oh, Org. Electron 25 (2015) 206, http://dx.doi.org/10.1016/ j.orgel.2015.06.018.

[9] H. Wang, Y. Zhu, Z. Liu, L. Zhang, J. Chen, Y. Cao, Org. Electron 31 (2015) 1, http://dx.doi.org/10.1016/j.orgel.2015.12.030.

[10] N.M. O'Boyle, C.M. Campbell, G.R. Hutchison, J. Phys. Chem. C 115 (2011) 16200, http://dx.doi.org/10.1021/jp202765c.

[11] E.F. Oliveira, A. Camilo Jr., L.C. da Silva-Filho, F.C. Lavarda, J. Polym. Sci. Part B Polym. Phys. 51 (2013) 842, http://dx.doi.org/10.1002/polb.23274.

[12] E.F. Oliveira, F.C. Lavarda, Mater. Chem. Phys. 148 (2014) 923, http:// dx.doi.org/10.1016/j.matchemphys.2014.09.002.

[13] Y. Liang, Z. Xu, J. Xia, S.T. Tsai, Y. Wu, G. Li, C. Ray, L. Yu, Adv. Mater 22 (2010) E135, http://dx.doi.org/10.1002/adma.200903528.

[14] L. Lu, L. Yu, Adv. Mater 26 (2014) 441, http://dx.doi.org/10.1002/ adma.201400384.

[15] H.Y. Chen, J. Hou, S. Zhang, Y. Liang, G. Yang, Y. Yang, L. Yu, Y. Wu, G. Li, Nat. Phot 3 (2009) 649, http://dx.doi.org/10.1038/nphoton.2009.192.

[16] W. Kim, J.K. Kim, E. Kim, T.K. Ahn, D.H. Wang, J.H. Park, J. Phys. Chem. C 119 (2015) 5954, http://dx.doi.org/10.1021/jp510996w.

[17] S. Das, J.K. Keum, J.F. Browning, G. Gu, B. Yang, O. Dyck, C. Do, W. Chen, J.H. Chen, I.N. Ivanov, K.L. Hong, A.J. Rondinone, P.C. Joshi, D.B. Geohegan, G. Duscher, K. Xiao, Nanoscale 7 (2015) 15576, http://dx.doi.org/10.1039/ c5nr03332b.

[18] J.E. McMurry, Organic Chemistry, Cengage Learning, Stanford, CA, 2004

[19] K. Müllen, G. Wegner, Electronic Materials: the Oligomer Approach, WileyVCH, Weinheim, 1998.

[20] A. Batagin-Neto, E.F. Oliveira, C.F.O. Graeff, F.C. Lavarda, Mol. Simul. 39 (2013) 309, http://dx.doi.org/10.1080/08927022.2012.724174.

[21] J.J.P. Stewart, J. Mol. Model 13 (2007) 1173, http://dx.doi.org/10.1007/s00894007-0233-4.

[22] J.J.P. Stewart, MOPAC: Molecular Orbital Package, Stewart Computational Chemistry, 2012. Available at: http://www.openmopac.net/MOPAC2012.html.

[23] E.F. Oliveira, F.C. Lavarda, Mat. Res. 17 (2014) 1369, http://dx.doi.org/10.1590/ 1516-1439.278814.

[24] E.F. Oliveira, F.C. Lavarda, Polym. Eng. Sci. 56 (2016) 479, http://dx.doi.org/ 10.1002 /pen.24275.

[25] E.F. Oliveira, F.C. Lavarda, J. Polym. Sci. Part B Polym. Phys. 51 (2013) 1350, http://dx.doi.org/10.1002/polb.23338.

[26] R.C. Hiorns, P. Iratçabal, D. Bégué, A. Khoukh, R. De Bettignies, J. Leroy, M. Firon, C. Sentein, H. Martinez, H. Preud'homme, C. Dagron-Lartigau, J. Polym. Sci. Part A Polym. Chem. 47 (2009) 2304, http://dx.doi.org/10.1002/ pola.23311.

[27] R.C. Hiorns, E. Cloutet, E. Ibarboure, L. Vignau, N. Lemaitre, S. Guillerez, C. Absalon, H. Cramail, Macromolecules 42 (2009) 3549, http://dx.doi.org/ 10.1021/ma900279a.

[28] A.D. Becke, J. Chem. Phys. 98 (1993) 1372, http://dx.doi.org/10.1063/1.464304.

[29] A.D. Becke, J. Chem. Phys. 98 (1993) 5648, http://dx.doi.org/10.1063/1.464913.

[30] M.J. Frisch, G.W. Trucks, H.B. Schlegel, G.E. Scuseria, M.A. Robb, J.R. Cheeseman, G. Scalmani, V. Barone, B. Mennucci, G.A. Petersson, H. Nakatsuji, M. Caricato, X. Li, H.P. Hratchian, A.F. Izmaylov, J. Bloino, G. Zheng, J.L. Sonnenberg, M. Hada, M. Ehara, K. Toyota, R. Fukuda, J. Hasegawa, M. Ishida, T. Nakajima, Y. Honda, O. Kitao, H. Nakai, T. Vreven, J.A. Montgomery Jr., J.E. Peralta, F. Ogliaro, M. Bearpark, J.J. Heyd, E. Brothers, K.N. Kudin, V.N. Staroverov, R. Kobayashi, J. Normand, K. Raghavachari, A. Rendell, J.C. Burant, S.S. Iyengar, J. Tomasi, M. Cossi, N. Rega, J.M. Millam, M. Klene, J.E. Knox, J.B. Cross, V. Bakken, C. Adamo, J. Jaramillo, R. Gomperts, R.E. Stratmann, O. Yazyev, A.J. Austin, R. Cammi, C. Pomelli, J.W. Ochterski, R.L. Martin, K. Morokuma, V.G. Zakrzewski, G.A. Voth, P. Salvador, J.J. Dannenberg, S. Dapprich, A.D. Daniels, Ö. Farkas, J.B. Foresman, J.V. Ortiz, J. Cioslowski, D.J. Fox, 09, Revision D. 01, Gaussian. Inc., Wallingford, CT, 2009.

[31] W.J. Hehre, A Guide to Molecular Mechanics and Quantum Chemical Calculations, Wavefunction, Inc., Irvine, CA, 2003.

[32] T.M. McCormick, C.R. Bridges, E.I. Carrera, P.M. DiCarmine, G.L. Gibson, 
J. Hollinger, L.M. Kozycz, D.S. Seferos, Macromolecules 46 (2013) 3879, http:// dx.doi.org/10.1021/ma4005023.

[33] S.F. Sousa, P.A. Fernandes, M.J.G. Ramos, J. Phys. Chem. A 111 (2007) 10439, http://dx.doi.org/10.1021/jp0734474.

[34] M.A.L. Marques, E.K.U. Gross, Annu. Rev. Phys. Chem. 55 (2004) 427, http:// dx.doi.org/10.1146/annurev.physchem.55.091602.094449.

[35] R.S. Bhatta, D.S. Perry, M. Tsige, J. Phys. Chem. A 117 (2013) 12628, http:// dx.doi.org/10.1021/jp409069d.

[36] R.S. Bhatta, M. Tsige, ACS Appl. Mater. Interfaces 6 (2014) 15889, http:// dx.doi.org/10.1021/am5035126.

[37] W. Huang, E. Gann, Z.Q. Xu, L. Thomsen, Y.B. Cheng, C.R. McNeill, J. Mater. Chem. A 3 (2015) 16313, http://dx.doi.org/10.1039/C5TA04129E.

[38] R. Colle, G. Grosso, A. Ronzani, C. Zicovich-Wilson, Phys. Status Solidi B 6 (2011) 1360, http://dx.doi.org/10.1002/pssb.201046429.

[39] S. Grimme, J. Antony, S. Ehrlich, H. Krieg, J. Chem. Phys. 132 (2010) 154104, http://dx.doi.org/10.1063/1.3382344.

[40] S.S. Zade, M. Bendikov, Chem. Eur. J. 13 (2007) 3688, http://dx.doi.org/ 10.1002/chem.200600819.

[41] W. Zhuang, A. Lundin, M.R. Andersson, J. Mater. Chem. A 2 (2014) 222, http:// dx.doi.org/10.1039/C3TA14456A.

[42] B. Milián-Medina, A. Van-Vooren, P. Brocorens, J. Gierschner, M. Shkunov, M. Heeney, I. McCulloch, R. Lazzaroni, J. Cornil, Chem. Mater 19 (2007) 4949, http://dx.doi.org/10.1021/cm071279m.

[43] R.S. Bhatta, M. Tsige, D.S. Perry, J. Comput. Theor. Nanos 11 (2014) 2157, http://dx.doi.org/10.1166/jctn.2014.3621.

[44] W. Kuhn, Helv. Chim. Acta 31 (1948) 1780, http://dx.doi.org/10.1002/ hlca.19480310602.

[45] J. Gierschner, J. Cornil, H.-J. Egelhaaf, Adv. Mater 19 (2007) 173, http:// dx.doi.org/10.1002/adma.200600277.

[46] E.F. Oliveira, J.C. Roldao, B. Milián-Medina, F.C. Lavarda, J. Gierschner, Chem. Phys. Lett. 645 (2016) 169, http://dx.doi.org/10.1016/j.cplett.2015.12.059.

[47] J. Torras, J. Casanovas, C. Alemán, J. Phys. Chem. A 116 (2012) 7571, http:|| dx.doi.org/10.1021/jp303584b.

[48] S. Zade, N. Zamoshchik, M. Bendikov, Acc. Chem. Res. 44 (2010) 14, http:// dx.doi.org/10.1021/ar1000555.

[49] T. Heine, J. Joswig, A. Gelessus, Computational Chemistry Workbook, John Wiley \& Sons, Nova Jersey, NJ, 2009.

[50] K. Takimiya, I. Osaka, M. Nakano, Chem. Mater 26 (2014) 587, http:// dx.doi.org/10.1021/cm4021063.

[51] J.-L. Brédas, Mater. Horiz. 1 (2014) 17, http://dx.doi.org/10.1039/c3mh00098b.

[52] N. Leclerc, P. Chávez, O.A. Ibraikulov, T. Heiser, P. Lévêque, Polymers 8 (2016) 11, http://dx.doi.org/10.3390/polym8010011.

[53] Z. Fei, P. Boufflet, S. Wood, J. Wade, J. Moriarty, E. Gann, E.L. Ratcliff, C.R. McNeill, H. Sirringhaus, J.-S. Kim, M. Heeney, J. Am. Chem. Soc. 137 (2015) 6866, http://dx.doi.org/10.1021/jacs.5b02785.

[54] B. Carsten, J.M. Szarko, H.J. Son, W. Wang, L. Lu, F. He, B.S. Rolczynski, S.J. You, L.X. Chen, L. Yu, J. Am. Chem. Soc. 133 (2011) 20468, http://dx.doi.org/ $10.1021 / \mathrm{ja} 208642 \mathrm{~b}$

[55] M. Zhang, X. Guo, S. Zhang, J. Hou, Adv. Mater 26 (2014) 1118, http:// dx.doi.org/10.1002/adma.201304427.

[56] F. Carey, R.J. Sundberg, Springer: New York, Adv. Org. Chem. Part A Struct. Mech. 5 (2007) 123-177 (Chapter 3).

[57] Z. Li, H.C. Wong, Z. Huang, H. Zhong, C.H. Tan, W.C. Tsoi, J.S. Kim, J.R. Durrant J.T. Cabral, Nat. Commun. 4 (2013) 2227, http://dx.doi.org/10.1038 ncomms3227. 